\title{
Blood coagulation status of small-for-dates and postmature infants
}

\author{
M. PERLMAN*, and A. DVILANSKY \\ From the Neonatal Unit and Blood Research Laboratory, Soroka Medical Centre, Beersheba, Israel
}

\begin{abstract}
Perlman, M., and Dvilansky, A. (1975). Archives of Disease in Childhood, 50, 424. Blood coagulation status of small-for-dates and postmature infants. In a prospective study of blood coagulation status in small-for-dates and postmature infants there was often evidence of intravascular coagulation. Abnormal coagulation findings correlated with the degree of growth retardation and with the degree of postmaturity. Macroscopical placental infarction and neonatal polycythaemia were associated with coagulation abnormalities; asphyxia, however, was not. Intravascular coagulation may be an additional hazard to small-for-dates and postmature infants.
\end{abstract}

The material presented here is part of a broader prospective study of blood coagulation in term newborn infants. Described in the past as 'dysmature', two groups of infants, small-for-dates and postmature, are considered together as they have much in common, both during intrauterine life (fetal malnutrition, hypoxia, fetal distress, and polycythaemia), and postnatally (neonatal asphyxia, intracranial haemorrhage, and hypoglycaemia). Of these, asphyxia and polycythaemia are recognized causes of coagulopathies in infants. An additional aspect that we wished to explore was the possibility of preventing intracranial haemorrhage in neonates through early recognition and treatment of defects of blood coagulation.

\section{Clinical material}

Three groups of infants were studied; all were born at the Soroka Medical Centre between November 1971 and October 1972.

Normal controls. Normal infants of gestational age between 39 and 41 weeks and birthweight between

\section{Abbreviations}

PT: prothrombin time

TT: thrombin time

PTT: partial thromboplastin time

FDP: fibrin, fibrinogen degradation products

Received 13 November 1974.

^Present address: Neonatal Unit, Paediatric Department, Hadassah University Hospital, Jerusalem, Israel. the 25th and 75th centiles (standards of Thomson, Billewicz, and Hytten, 1968).

Small-for-dates infants. Gestational age of more than 38 and less than 42 completed weeks, and birthweight less than the 5th centile for gestational age and sex. External signs were appropriate to gestational age.

Postmature infants. Gestational age of more than 42 completed weeks and appropriate external signs. The latter were graded according to Clifford (1954).

Infants with conditions predisposing to sepsis and with clinical evidence of infection were excluded. In addition, blood cultures taken at the time of blood sampling were negative in all infants. No selection was applied in relation to complications of pregnancy and parturition in the two study groups.

The cord was usually clamped 30-60 seconds after birth. The placenta was inspected macroscopically for gross pathology. Routine care included injection of $0.5 \mathrm{mg}$ vitamin $\mathrm{K}$ within 2 hours of birth, and serial measurement of blood glucose in study group infants. Small-for-dates and postmature infants received a commercial milk preparation and/or breast feeding from the age of 6 hours, while control infants were breast fed from the age of 18-24 hours.

Definitions. Perinatal asphyxia: detection of the presence of fetal bradycardia and/or an Apgar score of less than 6 at one minute and less than 8 at 5 minutes. The placenta was considered abnormal when described in the labour ward record as extensively infarcted. Hypoglycaemia was defined by conventional criteria (Cornblath and Schwartz, 1966). Polycythaemia: capillary blood haematocrit exceeding $75 \%$. Subarachnoid haemorrhage: consistent blood-staining of three 


\section{Blood coagulation status of small-for-dates and postmature infants}

consecutive samples of CSF, and the findings of crenated erythrocytes on microscopical examination of freshly drawn fluid.

\section{Materials and methods}

Blood samples were taken from the external jugular or femoral vein using a 19-gauge siliconized needle and plastic syringe. The mean age of blood sampling was 26 hours, range 1-72 h. The majority of infants had a single study only. Particular attention was paid to rapid sampling of free-flowing blood in order to avoid contamination by tissue thromboplastin and initiation of clotting in vitro.

The following parameters of blood coagulation were estimated by methods outlined in a previous publication (Dvilansky and Biran, 1973): PT, TT, PTT, fibrinogen, Factor V, Factor VIII, plasminogen, euglobulin lysis time, FDP, and platelets. Half volumes of blood were used. The microhaematocrit was measured in capillary blood. Tests were performed by the same technician within 0.5 hour of collection of blood in plastic tubes kept in crushed ice. All coagulation determinations were made with a BBL Fibrometer.

Results of blood coagulation studies as well as clinical data were processed and analysed with the aid of a CDC Control Data 6600 computer. Statistical significance was examined by Student's ' $t$ ' test for small samples (Snedecor and Cochran, 1967).

\section{Results}

\section{Clinical findings (Table I).}

Normal controls. 17 males and 18 females were examined, their respective mean birthweights were 3445 and $3295 \mathrm{~g}$. Mean head circumference was $35 \mathrm{~cm}$ for males and $34 \cdot 1 \mathrm{~cm}$ for females.
Small-for-dates infants. 15 infants were male and 11 female; mean birthweight was $2320 \mathrm{~g}$. In the majority the cause of the low birthweight was not clear. One mother suffered from chronic renal disease and 3 from pre-eclamptic toxaemia. 3 infants were the smaller of twins by a difference of 14 to $26 \%$ of the larger twin. 11 of 14 singleton infants who were the products of multiparous mothers had birthweights lower than their sibs. Evidence of perinatal asphyxia was found in 11 infants. The placenta was macroscopically abnormal in 5 cases.

No infants had evidence of haemostatic failure. 2 infants delivered by vacuum extractor had a large subaponeurotic cephalhaematoma which expanded the head circumference and was associated with a low haematocrit. Another infant with a bulging fontanelle had evidence of a subarachnoid haemorrhage. 2 infants had hypoglycaemia and 4 had polycythaemia. 4 infants had transient neurological findings including lethargy, hypotonia, weak cry, irritability, and depressed Moro reflex.

Postmature infants. Mean birthweight was lower and mean head circumference higher than in normal controls. The male to female sex ratio was 3 to 1 ; birthweight and head circumference data (Table I) indicated a male disadvantage. Pregnancy complications were rarely recognized in this group, but this may reflect self-selection of mothers who were relatively neglected from the point of view of antenatal care and hence the prolonged pregnancy. Evidence of perinatal asphyxia was common

\section{TABLE I}

Clinical data on control, small-for-dates, and postmature cases

\begin{tabular}{|c|c|c|c|c|}
\hline & Control & Small-for-dates & Postmature & Total \\
\hline $\begin{array}{l}\text { No. } \\
\text { Gestational age (mean) (w) } \\
\text { Maternal toxaemia, hypertension } \\
\text { Ratio: male/female } \\
\text { Birthweight (mean) (g) } \\
\text { Males } \\
\text { Females } \\
\text { Head circumference (mean) (cm) } \\
\text { Males } \\
\text { Females } \\
\text { Fetal bradycardia } \\
\text { Severe meconium staining } \\
\text { Apgar score } 7 \text { at } 5 \text { min } \\
\text { Macroscopical placental infarction } \\
\text { Polycythaemia } \\
\text { Hypoglycaemia } \\
\text { Traumatic bleeding } \\
\text { Subarachnoid haemorrhage } \\
\text { Gastrointestinal bleeding } \\
\text { Neurological symptoms }\end{array}$ & $\begin{array}{c}35 \\
40 \cdot 3 \\
0 \\
17 / 18 \\
3445 \\
3295 \\
35 \cdot 0 \\
34 \cdot 1 \\
0 \\
0 \\
0 \\
0 \\
0 \\
0 \\
0 \\
0 \\
0 \\
0\end{array}$ & $\begin{array}{c}26 \\
39 \cdot 6 \\
5 \\
15 / 11 \\
2355 \\
2245 \\
33 \cdot 0 \\
32 \cdot 1 \\
6 \\
6 \\
4 \\
4 \\
5 \\
2 \\
2 \\
1 \\
0 \\
4\end{array}$ & $\begin{array}{c}30 \\
42 \cdot 7 \\
3 \\
27 / 9 \\
\\
3225 \\
3365 \\
\\
35 \cdot 0 \\
35 \cdot 6 \\
13 \\
12 \\
8 \\
9 \\
3 \\
2 \\
6 \\
3 \\
2 \\
13\end{array}$ & $\begin{array}{r}- \\
8 \\
- \\
- \\
- \\
- \\
19 \\
18 \\
12 \\
13 \\
8 \\
4 \\
8 \\
4 \\
2 \\
17\end{array}$ \\
\hline
\end{tabular}


TABLE II

Limited coagulation data comparing different grades of severity of small-for-dates and postmature cases

\begin{tabular}{|c|c|c|c|c|c|c|}
\hline & \multirow[b]{2}{*}{ Normal infants } & \multicolumn{3}{|c|}{ Small-for-dates infants } & \multicolumn{2}{|c|}{ Postmature infants } \\
\hline & & Stage I & Stage II & Stage III & Stage I & Stages II \& III \\
\hline No. & 35 & 12 & 9 & 5 & 18 & 12 \\
\hline Haematocrit (\%) & $61 \cdot 5 \pm 7$ & $67 \cdot 6 \pm 9 \cdot 1^{\star}$ & $65 \cdot 7 \pm 7 \cdot 1$ & $63 \cdot 0 \pm 10 \cdot 1$ & $68 \cdot 0 \pm 9 *$ & $68 \cdot 6 \pm 6 \cdot 9 t$ \\
\hline $\begin{array}{l}\text { Platelet count } \\
\qquad\left(\times 10^{3} / \mathrm{mm}^{3}\right)\end{array}$ & $169 \pm 43$ & $128 \cdot 4 \pm 38 \cdot 4^{\star}$ & $118 \cdot 2 \pm 46 \cdot 1 \dagger$ & $118 \cdot 8 \pm 53 \cdot 6 \star$ & $138 \cdot 6 \pm 31 \cdot 8^{\star}$ & $113 \cdot 6 \pm 70 \cdot 4 t$ \\
\hline PT (s) & $11 \cdot 1 \pm 0 \cdot 7$ & $12 \cdot 6 \pm 2 \cdot 7^{\star}$ & $11 \cdot 1 \pm 1 \cdot 6$ & $12 \cdot 7 \pm 1 \cdot 5^{\star}$ & $11 \cdot 5 \pm 1 \cdot 8$ & $11 \cdot 6 \pm 1 \cdot 9$ \\
\hline $\mathbf{T T}(\mathbf{s})$ & $13 \cdot 4 \pm 1 \cdot 3$ & $13 \cdot 6 \pm 2 \cdot 3$ & $14 \cdot 2 \pm 2 \cdot 4$ & $15 \cdot 7 \pm 1 \cdot 9 \star$ & $14 \cdot 3 \pm 2 \cdot 3 \star$ & $15 \cdot 4 \pm 1 \cdot 9 t$ \\
\hline PTT (s) & $47 \cdot 1 \pm 7 \cdot 9$ & $63 \cdot 2 \pm 11 \cdot 4 t$ & $53 \cdot 3 \pm 10 \cdot 7^{\star}$ & $60 \cdot 0 \pm 14 \cdot 2^{\star}$ & $52 \cdot 5 \pm 10 \cdot 9 \star$ & $45 \cdot 8 \pm 11 \cdot 8$ \\
\hline Fibrinogen (mg/dl) & $184 \pm 66$ & $164 \cdot 3 \pm 42$ & $155 \cdot 8 \pm 34 \cdot 5$ & $154 \cdot 6 \pm 53 \cdot 5$ & $179 \cdot 9 \pm 39$ & $160 \pm 46 \cdot 6$ \\
\hline
\end{tabular}

Values given as mean $\pm S D . \quad \star 0.005<P<0.05 .+P<0.005$.

(Table I). The placenta was macroscopically abnormal in 8 instances.

Two infants had gastrointestinal bleeding at the age of 1 and 4 days, respectively; 3 had evidence of subarachnoid haemorrhage. Hypoglycaemia was detected in 2 instances. 13 infants had neurological signs during the first postnatal days; 2 also had a convulsive disorder. Meconium aspiration pneumonitis with bilateral pneumothoraces occurred in one infant.

Blood coagulation data (Tables II and III).

Normal controls. Values for Factors I, V, and VIII are similar to those reported by others
(Bleyer, Hakami, and Shepard, 1971). PT did not differ from adult values, while PTT was prolonged. The platelet count was lower than that reported in other studies (Sell and Corrigan, 1973), as is the normal range for platelets in adults in this laboratory $\left(120000-300000 / \mathrm{mm}^{3}\right)$. The highest value of FDP in a normal infant was $2 \cdot 4$ $\mu \mathrm{g} / \mathrm{ml}$. When postnatal age was related to the laboratory values including FDP, the relation was significant only for fibrinogen, the values of which rose during the first $\mathbf{4 8}$ postnatal hours, an observation which has been made by other workers (Ekelund, Hedner, and Nilsson, 1970).

Small-for-dates infants. Selected results ob-

TABẺE

Coagulation values in relationộto

\begin{tabular}{|c|c|c|c|}
\hline & Normal controls & $\begin{array}{l}\text { Uncomplicated SFD } \\
\text { and PM infants }\end{array}$ & $\begin{array}{l}\text { Asphyxiated SFO } \\
\text { and PM infants }\end{array}$ \\
\hline $\begin{array}{l}\text { No. } \\
\text { Haematocrit }(\%) \\
\text { Platelets }\left(\times 10^{3} / \mathrm{mm}^{3}\right) \\
\text { PT }(\mathrm{s}) \\
\text { TT (s) } \\
\text { PTT }(\mathrm{s}) \\
\text { Factor V }(\%) \\
\text { Factor VIII (\%) } \\
\text { Fibrinogen (mg/dl) } \\
\text { Plasminogen units } \\
\text { (min) } \\
\text { Euglobulin lysis time } \\
\quad(\mathrm{min}) \\
\text { FDP }(\mu \mathrm{g} / \mathrm{ml}) \\
\text { Haemoglobin (g/dl) }\end{array}$ & $\begin{array}{c}35 \\
61 \cdot 5 \pm 7 \cdot 0 \\
169 \cdot 1 \pm 42 \cdot 9 \\
11 \cdot 1 \pm 0 \cdot 7 \\
13 \cdot 4 \pm 1 \cdot 3 \\
47 \cdot 1 \pm 7 \cdot 9 \\
98 \cdot 0 \pm 42 \cdot 9 \\
137 \cdot 2 \pm 83 \cdot 8 \\
184 \cdot 2 \pm 65 \cdot 7 \\
\\
1 \cdot 81 \pm 0 \cdot 81 \\
140 \cdot 2 \pm 58 \cdot 9 \\
0 \cdot 79 \pm 0 \cdot 81 \\
21 \cdot 5 \pm 2 \cdot 6\end{array}$ & $\begin{array}{c}14 \\
68 \cdot 0 \pm 5 \cdot 8^{\star} \\
130 \cdot 3 \pm 43 \cdot 9^{\star} \\
11 \cdot 8 \pm 2 \cdot 2^{\star} \\
14 \cdot 7 \pm 2 \cdot 4^{\star} \\
56 \cdot 7 \pm 11 \cdot 8^{\star} \\
102 \cdot 8 \pm 45 \cdot 8 \\
115 \cdot 7 \pm 49 \cdot 6 \\
158 \cdot 2 \pm 36 \cdot 2 \\
1 \cdot 44 \pm 0 \cdot 68 \\
123 \cdot 2 \pm 67 \cdot 8 \\
1 \cdot 31 \pm 1 \cdot 21 \\
23 \cdot 1 \pm 2 \cdot 5^{\star}\end{array}$ & 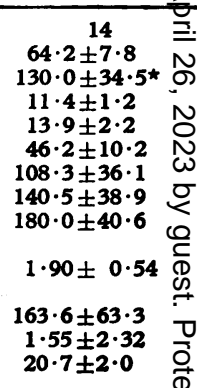 \\
\hline $.005<P<0.05$ & 0.005 & & 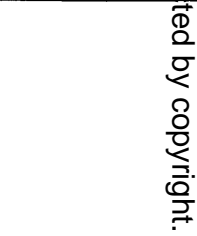 \\
\hline
\end{tabular}


tained for the 26 infants are aggregated in groups by birthweight and summarized in Table II. Platelets were significantly diminished; PT, TT, and PTT increased, and the values of FDP were increased. In the case of platelets, TT, and FDP, the values were aberrant in proportion to the severity of the growth retardation (Table II). No significant alterations were observed in the levels of fibrinogen and Factors V and VIII.

Postmature infants. For the purpose of analysis of results this group was divided into two: (a) grade I (18 infants); (b) grades II and III (12 infants) (Clifford, 1954).

The clinical severity of the postmaturity was reflected in the abnormal laboratory values, particularly platelets, TT, fibrinogen, and FDP (Table II).

Uncomplicated small-for-dates and postmature infants. A control group of small-for-dates and postmature infants without prenatal or postnatal complications was selected for comparison (Table III). When compared with normal controls, uncomplicated small-for-dates and postmatures were associated with a raised haematocrit, diminished platelet count, and prolonged PT, TT, and PTT.

Other clinicopathological associations (Table III). The effect of a number of perinatal complications upon blood coagulation values was examined. Results for the two study groups were pooled for analysis.

Asphyxia was not associated with significant alterations of laboratory values. Gross placental infarction (13 cases), polycythaemia (8 cases), and hypoglycaemia (4 cases) were each significantly correlated with thrombocytopenia, prolonged TT and PTT, and increased FDP values. 2 infants with spontaneous gastrointestinal bleeding had normal coagulation values. 4 infants with subarachnoid haemorrhage had a mean haematocrit of $70 \%$. In addition, there was thrombocytopenia and increased FDP values but no evidence of bleeding tendency.

Examples are given in the Appendix to illustrate the various coagulation profiles observed in some of the more severely affected infants.

\section{Discussion}

Both categories of study group infants have been described as 'dysmature'. Small-for-dates and postmature infants have in common a high incidence of fetal hypoxia, malnutrition, polycythaemia (Humbert et al., 1969; McKay, 1957), perinatal asphyxia, hypoglycaemia, and possibly of placental 'ageing' (Scott and Jordan, 1972). The clinical data in Table I highlight the increased immediate morbidity rate of both small-for-dates and premature infants and show the similarities between them. Of interest is the preponderance of males in both study groups and the greater tendency to low birthweight for gestional age in the postmature group.

The study provides evidence that intravascular coagulation frequently occurs in small-for-dates and premature infants. The significantly altered laboratory values were increased TT and PTT, decreased platelets, and increased FDP. Thrombocytopenia was the only evidence of a consumption coagulopathy, but values of fibrinogen and Factors

various perinatal complications

\begin{tabular}{|c|c|c|c|}
\hline Placental pathology & Polycythaemia & Hypoglycaemia & $\begin{array}{l}\text { Subarachnoid } \\
\text { haemorrhage? }\end{array}$ \\
\hline $\begin{array}{c}13 \\
65 \cdot 0 \pm 12 \cdot 1 \\
97 \cdot 1 \pm 43 \cdot 9 \dagger \\
11 \cdot 7 \pm 1 \cdot 5^{\star} \\
15 \cdot 0 \pm 2 \cdot 7 \dagger \\
55 \cdot 7 \pm 14 \cdot 0^{\star} \\
81 \cdot 5 \pm 33 \cdot 4 \\
154 \cdot 3 \pm 70 \cdot 3 \\
169 \cdot 3 \pm 52 \cdot 2\end{array}$ & $\begin{array}{c}8 \\
77 \cdot 5 \pm 2 \cdot 4 \dagger \\
96 \cdot 8 \pm 39 \cdot 2 \dagger \\
11 \cdot 6 \pm 1 \cdot 6 \\
15 \cdot 5 \pm 2 \cdot 7 \dagger \\
59 \cdot 4 \pm 10 \cdot 1 \dagger \\
101 \cdot 0 \pm 60 \cdot 7 \\
178 \cdot 6 \pm 105 \cdot 4 \\
183 \cdot 3 \pm 37 \cdot 3\end{array}$ & $\begin{array}{c}5 \\
70 \cdot 4 \pm 5 \cdot 2^{\star} \\
68 \cdot 4 \pm 40 \cdot 1 \dagger \\
12 \cdot 0 \pm 2 \cdot 3 \\
15 \cdot 7 \pm 1 \cdot 7 \dagger \\
60 \cdot 3 \pm 15 \cdot 1 \dagger \\
94 \cdot 0 \pm 41 \cdot 9 \\
130 \cdot 4 \pm 84 \cdot 9 \\
156 \cdot 5 \pm 54 \cdot 6\end{array}$ & $\begin{array}{c}4 \\
69 \cdot 7 \pm 3 \cdot 9 \star \\
110 \cdot 7 \pm 42 \cdot 4^{\star} \\
10 \cdot 1 \pm 1 \cdot 1^{\star} \\
14 \cdot 4 \pm 3 \cdot 1 \\
48 \cdot 4 \pm 5 \cdot 5 \\
115 \cdot 1 \pm 63 \cdot 0 \\
160 \cdot 0 \pm 83 \cdot 7 \\
152 \cdot 0 \pm 19 \cdot 0\end{array}$ \\
\hline $1.45 \pm 0.51$ & $1 \cdot 49 \pm 0 \cdot 56$ & $1 \cdot 25 \pm 0 \cdot 54$ & $1 \cdot 66 \pm 0 \cdot 47$ \\
\hline $\begin{aligned} 187 \cdot 5 & \pm 134 \cdot 5 \\
6 \cdot 88 & \pm 10 \cdot 08 t \\
20 \cdot 7 & \pm 3 \cdot 0\end{aligned}$ & $\begin{array}{l}98 \cdot 8 \pm 101 \cdot 5 \\
7 \cdot 80 \pm 9 \cdot 77 t \\
24 \cdot 8 \pm 2 \cdot 5 t\end{array}$ & $\begin{array}{l}132 \cdot 0 \pm 54 \cdot 8 \\
7 \cdot 46 \pm 10 \cdot 98 t \\
21 \cdot 5 \pm 2 \cdot 6\end{array}$ & $\begin{array}{c}130 \cdot 0 \pm 80 \cdot 3 \\
2 \cdot 29 \pm 2 \cdot 83^{\star} \\
21 \cdot 5 \pm 3 \cdot 5\end{array}$ \\
\hline
\end{tabular}


$\mathrm{V}$ and VIII may be normal or increased in states of chronic or low-grade intravascular coagulation or during recovery (Cooper et al., 1971).

Infants of mothers with uncomplicated pregnancies and labours and in whom no abnormality other than being small-for-dates or postmature was detected had lesser deviations from normal laboratory values than those with additional obstetric complications (Table III). Of major importance were the findings of gross placental pathology and of polycythaemia; aspyhxia appeared to play no role in the observed changes (Table III). Infants with tissue bleeding had a low haematocrit and increased values of FDP. Neonatal hypoglycaemia was associated with particularly marked changes in the values of the haematocrit, platelet count, and FDP, and presumably represents the severity of the predisposing perinatal disturbances.

Owing to the presence of multiple pathogenetic factors in the majority of infants and the relatively small numbers studied it was not possible to evaluate the precise role of each factor in the production of the observed coagulation changes. However, three factors likely to be important are placental infarction, polycythaemia, and asphyxia.

The pivotal role of the placenta in blood coagulation is indicated from several lines of evidence. (1) Disseminated intravascular coagulation and consumption coagulopathy may occur as a result of placental abruption, in the neonate as well as in the mother (Nielsen, 1970; Leissring and Vorlicky, 1968). (2) Laboratory findings indicative of a hypercoagulable state have been detected in uterine venous blood taken during placental separation (Bonnar et al., 1970). (3) Fibrin clots have been observed by microcirculation techniques in both uterine and umbilical veins of experimental animals during placental separation (Brown and Stalker, 1969). (4) In complicated pregnancies placental cushion lesions have been found to be associated with portal venous, pulmonary arterial, and systemic capillary thromboembolic phenomena (deSa, 1973). The high concentration of thromboplastin in the placenta (Schneider, 1947) is probably of central importance in the mechanism of the above phenomena. Though there appears to be no specific placental lesion(s) in the small-fordates and postmature fetuses, there is probably an increased number of vascular lesions, ischaemic necrosis of villi, infarcts, and retroplacental haemorrhages (Scott and Jordan, 1972) in some instances. In the present study the correlation between placental infarction and blood coagulation changes consistent with intravascular coagulation suggests that the entry of placental thromboplastin into the fetal circulation is facilitated in a proportion of small-for-dates and postmature infants.

Polycythaemia is associated with laboratory changes compatible with mild intravascular coagulation in cyanotic congenital heart disease, presumably mediated through hyperviscosity of the blood (Komp and Sparrow, 1970). In addition, polycythaemia is not infrequently associated with neurological symptoms in the neonate (Kontras, 1972), and has been invoked as a cause of irreversible brain damage (Baum, 1967). Polycythaemia was clearly associated both with neurological symptoms and with coagulation changes in the present series.

Asphyxia was not a predisposing cause of coagulopathies in our cases contrary to the findings of some investigators (Chadd et al., 1971), but in agreement with others (Ekelund and Finnström, 1972). Anoxic tissue damage such as that possibly seen in Case 3 (Appendix) may have contributed to intravascular coagulation by releasing tissue thromboplastin into the circulation. The question arises as to whether the coagulation changes found in asphyxiated infants in other studies were not due to unrecognized asphyxia-associated factors such as polycythaemia or placental lesions.

Apart from consumption coagulopathy, the important implication of intravascular coagulation is tissue ischaemia and infarction. A placental mechanism, as suggested above, could result in embolization of fibrin clots via the fetal cardiovascular shunts to the brain and other organs. This may have more sinister implications than the observed pulmonary effects of fibrin embolization from the maternal side of the placenta in preeclamptic and eclamptic mothers (Birmingham Eclampsia Study Group, 1971). No evidence of necrotic pathological lesions was detected in the perinatal period in the infants studied; there was, however, a high incidence of neurological symptoms.

Although infants with subarachnoid haemorrhage had altered coagulation tests, the bleeding could not be attributed to a consumption coagulopathy. Necrotic pathological lesions due to intravascular coagulation, or, increased venous pressure due to polycythaemia, are possible alternative mechanisms.

The prevention of postnatal polycythaemia may be justified in infants at risk, by preventing the placental transfusion, or by phlebotomy or partial exchange transfusion with plasma. Ultimately, the early recognition of fetal distress and the establishment of criteria for obstetric intervention are probably more important approaches to the coagulation disorders of small-for-dates and postmature infants. 
This work was made possible by a grant from the University of the Negev, Beersheba, Israel.

\section{REFERENCES}

Baum, R. S. (1967). Hyperviscous blood and perinatal pethology. (Abst.). Pediatric Research, 1, 288.

Birmingham Eclampsia Study Group (1971). Intravascular coagulation and abnormal lung-scans in pre-eclampsia and eclampsia. Lancet, 2, 889.

Bleyer, W. A., Hakami, N., and Shepard, T. H. (1971). The development of hemostasis in the human fetus and newborn infant. Fournal of Pediatrics, 79, 838.

Bonnar, J., Prentice, C. R. M., McNicol, G. P., and Douglas, A. S. (1970). Haemostatic mechanism in the uterine circulation during placental separation. British Medical fournal, 2, 564.

Brown, L. J., and Stalker, A. L. (1969). Experimental defibrination III. The maternal and foetal microcirculation following placental separation or trauma. Microvascular Research, 1, 403.

Chadd, M. A., Elwood, P. C., Gray, O. P., and Muxworthy, S. M. (1971). Coagulation defects in hypoxic full-term newborn infants. British Medical Fournal, 4, 516.

Clifford, S. H. (1954). Postmaturity-with placental dysfunction. Fournal of Pediatrics, 44, 1.

Cooper, H. A., Bowie, E. J. W., Didisheim, P., and Owen, C. A., Jr. (1971). Paradoxic changes in platelets and fibrinogen in chronically induced intravascular coagulation. Mayo Clinic Proceedings, 46, 521.

Cornblath, M., and Schwartz, R. (1966). Disorders of Carbohydrate Metabolism in Infancy. Saunders, Philadelphia.

deSa, D. J. (1973). Intimal cushions in foetal placental veins. fournal of Pathology, 110,347.

Dvilansky, A., and Biran, H. (1973). Hypofibrinogenemia after echis colorata bite in man. Acta Haematologica, 49, 123.

Edson, J. R., Blaese, R. M., White, J. G., and Krivit, W. (1968). Defibrination syndrome in an infant born after abruptio placentae. Fournal of Pediatrics 72, 342.

Ekelund, H., and Finnström, O. (1972). Fibrinolysis in pre-term infants and in infants small for gestational age. Acta Paediatrica Scandinavica, 61, 185.

Ekelund, H., Hedner, U., and Nilsson, I. M. (1970). Fibrinolysis in newborns. Acta Paediatrica Scandinavica, 59, 33.

Humbert, J. R., Abelson, H., Hathaway, W. E., and Battaglia, F. C. (1969). Polycythemia in small for gestional age infants. Fournal of Pediatrics, 75, 812 .

Komp, D. M., and Sparrow, A. W. (1970). Polycythemia in cyanotic heart disease-a study of altered coagulation. Fournal of Pediatrics, 76, 231.

Kontras, S. B. (1972). Polycythemia and hyperviscosity syndromes in infants and children. Pediatric Clinics of North America, 19, 919.

Leissring, J. C., and Vorlicky, L. N. (1968). Disseminated intravascular coagulation in a neonate. American Fournal of Diseases of Children, 115, 100.

McKay, R. B. (1957). Observations on the oxygenation of the fetus in normal and abnormal pregnancy. Fournal of Obstetrics and Gynaecology of the British Empire, 64, 185.

Nielsen, N. C. (1970). Coagulation and fibrinolysis in mothers and their newborn infants following premature separation of the placenta. Acta Obstetrica Gynecologica Scandinavica, 49, 77.

Schneider, C. L. (1947). The active principle of placental toxin, thromboplastin; its inactivator in the blood: antithromboplastin. American fournal of Physiology, 149, 123.

Scott, J. M., and Jordan, J. M. (1972). Placental insufficiency and the small-for-dates baby. American Fournal of Obstetrics and Gynecology, 113, 823.

Sell, E. J., and Corrigan, J. J. (1973). Platelet counts, fibrinogen concentrations, and factor $\mathrm{V}$ and factor VIII levels in healthy infants according to gestational age. Fournal of Pediatrics, 82, 1028.

Snedecor, G. W., and Cochran, W. G. (1967). Statistical Methods, 6th ed. Iowa State University Press, Ames, Iowa.

Thomson, A. M., Billewicz, W. Z., and Hytten, F. E. (1968). The assessment of fetal growth. Fournal of Obstetrics and Gynaecology of the British Commonwealth, 75, 903.

Correspondence to Dr. A. Dvilansky, The Soroka Medical Centre, Beersheba, Israel.

\section{Appendix}

Case 1. A 23-year-old para-2 gravida-2 mother delivered a female infant spontaneously by breech presentation, after 296 postmenstrual days. Apart from meconium-stained liquor, the pregnancy and parturition were normal. Apgar score was 9 at one minute. The placenta was infarcted, calcified, and deeply meconium stained. Physical examination revealed signs of stage II postmaturity. Birthweight was $3150 \mathrm{~g}$ and head circumference $35 \mathrm{~cm}$. Apart from asymmetry of the Moro reflex there were no abnormal physical findings.

At 28 hours the following abnormal tests of coagulation were documented: TT $15 \cdot 7 \mathrm{~s}$, FDP $14 \cdot 4 / \mu \mathrm{g} / \mathrm{ml}$, and platelets $96000 / \mathrm{mm}^{3}$. Other tests were normal.

On the fourth day a haematemasis occurred. At this time the only abnormalities in the coagulation profile were a platelet count of $86000 / \mathrm{mm}^{3}$ with the FDP value still $14 \cdot 4 \mu \mathrm{g} / \mathrm{ml}$. Hb fell from $21 \cdot 8 \mathrm{~g} / \mathrm{dl}$ on the second day to $17.8 \mathrm{~g}$ on the fourth day. The initial tests could be attributed to mild intravascular coagulation. The gastrointestinal bleeding on the fourth day could not, however, be attributed to a consumption coagulopathy. The sustained high value of the FDP is unexplained.

Case 2. This infant was the product of an uncomplicated second pregnancy. During delivery, viscid meconium-stained liquor and fetal bradycardia were noted. Apgar score was zero at birth, but the infant responded to external cardiac massage, artificial ventilation, and alkali administration. Deep meconium staining of skin and cord were seen; birthweight was $3450 \mathrm{~g}$ and head circumference $35 \mathrm{~cm}$.

After resuscitation, respiratory distress was noted and chest $x$-ray showed a picture of aspiration pneumonitis and bilateral small pneumothoraces. At $30 \mathrm{~min}$ blood sugar was $4 \mathrm{mg} / \mathrm{dl}$, this was corrected by infusion of $15 \%$ glucose. Subsequently convulsions occurred and the anterior fontanelle was noted to be tense. Lumbar puncture revealed evidence of a subarachnoid haemorrhage. There were residual neurological signs at the time of discharge at the age of 14 days.

Coagulation values on the fourth day were as follows: capillary haematocrit $80 \%$, platelet count $12000 / \mathrm{mm}^{3}$, TT $16.5 \mathrm{~s}$, and FDP $28.8 \mu \mathrm{g} / \mathrm{ml}$. After repeated phlebotomies totalling $60 \mathrm{ml}$, haematocrit and platelet count became normal. This complicated postmature infant had raised FDP on the fourth day postpartum, as well as severe thrombocytopenia. This may have been due to intravascular coagulation resulting from continuing tissue damage initiated by asphyxia, or to polycythaemia.

Case 3. This male infant was born to a gravida-7 mother aged 36 years. Her third pregnancy had ended in a stillbirth after 42 weeks' gestation. She had no antenatal care in this pregnancy and spontaneous labour occurred at 303 days. Severe bradycardia occurred during the first stage and delivery was accomplished by caesarean section. Apgar score was 1, 3, and 6 at 1,5 , and 10 minutes. Birthweight was $3120 \mathrm{~g}$ 
and head circumference $34.5 \mathrm{~cm}$. Signs typical of stage III postmaturity were present. The subsequent course was complicated by convulsions with hypoglycaemia (blood glucose $12 \mathrm{mg} / \mathrm{dl}$ at 4 hours) and hypocalcaemia $(7 \cdot 1 \mathrm{mg} / \mathrm{dl}$ on day 1$)$.

At 14 hours haematocrit was $76 \%$ and platelet count $30000 / \mathrm{mm}^{3}$. At 38 hours the following abnormal laboratory tests were recorded: capillary haematocrit $77 \%$, platelets $70000 / \mathrm{mm}^{3}$, TT $18 \cdot 2 \mathrm{~s}$, fibrinogen 98 $\mathrm{mg} / \mathrm{dl}$, plasminogen 0.4 units, and FDP $7 \cdot 2 \mu \mathrm{g} / \mathrm{ml}$. 2 days later the capillary haematocrit was $68 \%$, platelets $54000 / \mathrm{mm}^{3}$, TT $14 \cdot 5 \mathrm{~s}$, and FDP $7 \cdot 2 \mu \mathrm{g} / \mathrm{ml}$. The plasminogen value had risen to 1.3 units and other tests were normal.

At birth the SGOT value was 440 units and SGPT 190 units and on the 4th postnatal day, 820 and 610 units, respectively. This stage III postmature infant with asphyxia and hypoglycaemia had a persistently raised value of FDP and thrombocytopenia. SGOT and SGPT values indicated continuing tissue damage which might have accounted for the persistent findings of low-grade intravascular coagulation.

Case 4. A male infant was delivered after 295 postmenstrual days to a gravida- 5 mother aged 28 years. Pregnancy and parturition were uncomplicated and Apgar score was 9 at one minute. Birthweight was $3300 \mathrm{~g}$ and head circumference $35 \mathrm{~cm}$. External signs of postmaturity were noted but there was no meconium staining (stage I). At 48 hours a cyanotic spell occur- red; blood glucose values were 3 and $5 \mathrm{mg} / \mathrm{dl}$. Infusion of glucose $15 \%$ corrected the hypoglycaemia.

At 55 hours haematocrit was $71 \%$, platelet count $64000 / \mathrm{mm}^{3}$, TT $17 \cdot 9 \mathrm{~s}$, PTT $79 \mathrm{~s}$, and fibrinogen $82 \mathrm{mg} / \mathrm{dl}$. Euglobulin lysis time was $60 \mathrm{~min}$. LeeWhite silicone clotting time was $6 \mathrm{~min}$. PT, Factors V and VIII, and FDP values were normal.

This hypoglycaemic postmature infant had some of the criteria required for the diagnosis of disseminated intravascular coagulation, with hypercoagulability rather than a bleeding tendency. The normal FDP value may have been due to rapid clearance of these products.

Case 5. This female infant was the product of a 37-year-old mother, para-3, gravida-3. The birthweights of the 2 previous children were 3200 and $3400 \mathrm{~g}$. Gestation was 40 weeks, pregnancy and parturition were normal except for meconium staining of the liquor. Apgar score was 9 at one minute, birthweight $2600 \mathrm{~g}$, and head circumference $33.5 \mathrm{~cm}$. Apart from signs of malnutrition and gross meconium staining the infant appeared normal and the neonatal course was uncomplicated.

At 7 hours the capillary blood haematocrit was $80 \%$; platelet count $122000 / \mathrm{mm}^{3}$, TT $16 \cdot 9 \mathrm{~s}$, PTT $68 \cdot 2 \mathrm{~s}$, euglobulin lysis time $40 \mathrm{~min}$, and FDP $14.4 \mu \mathrm{g} / \mathrm{ml}$. Other coagulation parameters were normal.

This small-for-dates infant had laboratory findings partially consistent with the diagnosis of intravascular coagulation. Polycythaemia appeared to be a likely pathogenetic factor here. 